\title{
Necesitamos más enfermeras
}

\author{
Editorial
}

Da la sensación de que cada vez hay menos reticencias a reconocer en público, porque en privado hay muchos que ya lo hacen, el papel fundamental, presente pero sobre todo futuro, que las enfermeras tenemos en los sistemas de salud.

Llegar a este punto, suficiente para algunas enfermeras y demasiado exiguo para muchas otras, ha sido posible gracias al encomiable esfuerzo de muchas enfermeras pioneras, de muchas enfermeras empeñadas en romper barreras o en atravesar nuestro sempiterno techo de cristal.

Obviamente no ha sido ni será un proceso fácil. El camino ha estado y posiblemente seguirá estando plagado de críticas, denuncias y bloqueos desde los lobbies de otras profesiones sanitarias. Solo hay que ver el proceloso tránsito que está teniendo la regulación nacional de la prescripción enfermera o las denuncias por toda la geografía española contra decretos y resoluciones que permiten a las enfermeras asumir puestos de responsabilidad para comprobarlo.

En contraposición, el hecho de que algunas entidades y destacadas personalidades reconozcan en público este papel fundamental es una constatación de que el cambio empieza a ser una realidad. Que el nuevo director de la Organización Mundial de la Salud, el Sr. Tedrós Adhanom, reconozca este papel y lo refrende incluyendo a una enfermera en su equipo directivo o propiciando la campaña Nursing Now junto al CIE o que el exdirector de la Organización Nacional de Trasplantes, el Sr. Matesanz, reconozca el papel central y fundamental que han tenido y tienen las enfermeras en una organización de prestigio internacional, nos hacen pensar que es posible que se esté iniciando un nuevo momento para las enfermeras.

En algunos ámbitos asistenciales este nuevo momento empieza a ser una realidad y cada vez es menos infrecuente encontrar enfermeras gestionando equipos humanos y unidades de gestión clínica, siendo referentes de investigación y dirigiendo importantes proyectos o dirigiendo centros sanitarios, hospitales o incluso consejerías.

Sin embargo, existen aún entornos donde la capacidad de influencia de las enfermeras sigue siendo limitada. Entornos de decisión donde no nos dejan participar o donde nuestra opinión tiene menos peso que el de otras profesiones o menos peso que el que nos correspondería por responsabilidad directa.

Las enfermeras, como pieza clave en la sostenibilidad de los sistemas sanitarios, deberíamos ser referentes en cronicidad, en la atención a los pacientes frágiles, en las políticas de atención a la dependencia y en muchos otros ámbitos.

Y es indudable que las enfermeras debemos reclamar ese espacio de decisión también en todo lo relacionado con el cuidado de las heridas crónicas, ámbito en el que indudablemente las enfermeras somos las más competentes y en el que tenemos una responsabilidad directa.

No solo es cuestión de que las enfermeras debemos tener un papel importante en los sistemas de compra centralizados o en el diseño de los catálogos de productos para el cuidado de las heridas sino que debemos orientar una parte de nuestra actividad investigadora en este sentido.

El campo de la economía de la salud es, posiblemente, uno de los espacios donde las enfermeras menos se han desarrollado. La investigación en el campo de las heridas crónicas no solo debe circunscribirse a la efectividad de tal o cual apósito sino que debemos atrevernos a empezar a investigar sobre la eficiencia, sobre costes o sobre resultados en salud.

Estas son las líneas de investigación hacia donde un grupo de enfermeras hemos ido reorientando nuestros esfuerzos con los años pero necesitamos a más enfermeras que se atrevan a investigar sobre el impacto económico y en salud de sus decisiones, como de algún modo reclama el informe "La Aportación Enfermera a la Sostenibilidad del Sistema Sanitario. Repercusión Económica de los Cuidados" de la Fundación Economía y Salud.

Necesitamos a más enfermeras investigando sobre el impacto de los cuidados que prestan sobre la salud de los pacientes y también sobre el impacto económico que dichos cuidados tienen sobre el sistema en su conjunto.

Necesitamos a más enfermeras que salgan de los casos clínicos para atreverse a investigar sobre qué costes, en términos económicos pero también de salud, tienen sus decisiones.

\author{
Andoni Carrión Jiménez \\ Enfermero. Supervisor de Cuidados \\ Hospital de la Línea. Área de Gestión Sanitaria \\ Campo de Gibraltar \\ Servicio Andaluz de Salud
}

